\title{
4 YEARS' ROUTINE ADMINISTRATION OF PROBIOTICS TO HIGH-RISK NEONATES: RETROSPECTIVE AUDIT OF ADHERENCE TO LOCAL GUIDELINES
}

\section{Eleanor Brown, Sherif Dabbour, Raducu Clapuci, Paul Clarke Norfolk and Norwich University Hospitals WHS \\ NHS Foundation Trust}

\section{BACKGROUND AND AIMS}

Probiotics have been shown to reduce the risk of necrotising enterocolitis (NEC) in very low birthweight babies without adverse effects in RCTs studying $>5000$ babies $^{1-2}$.

Since January 2013, our tertiary-level NICU has offered probiotics routinely to high-risk neonates to prevent necrotising enterocolitis, using dual-strain Lactobacillus-Bifidobacteria (Infloran or Labinic).

Prior to reviewing the effect of probiotics on NEC and death rates within our clinical setting, it was noted that a 2016 retrospective observational study from the Netherlands did not identify an independent association between probiotic administration and reduced incidence of NEC or death ${ }^{3}$. One limiting factor was noted to be the possibility of untreated infants within the cohort. Before conducting our own study, we therefore audited adherence to local probiotic administration guidelines.

\section{GUIDELINE FOR PROBIOTIC USE}

$\rightarrow$ Babies $<32$ weeks' gestation or 32-36 weeks' gestation and $<1500$ g birthweight

Dose daily from day 0-1 after birth or transfer in, if the baby is eligible for milk feeds

- Dose until 34 weeks' corrected age (if born <32 weeks' gestation) or until discharge (VLBW babies born 32-36 weeks' gestation)

\section{METHODS}

Using Badgernet neonatal electronic records, we retrospectively reviewed probiotic administration in probiotic-eligible babies (without active NEC/sepsis concerns) admitted during the 4-year period 2013-16.

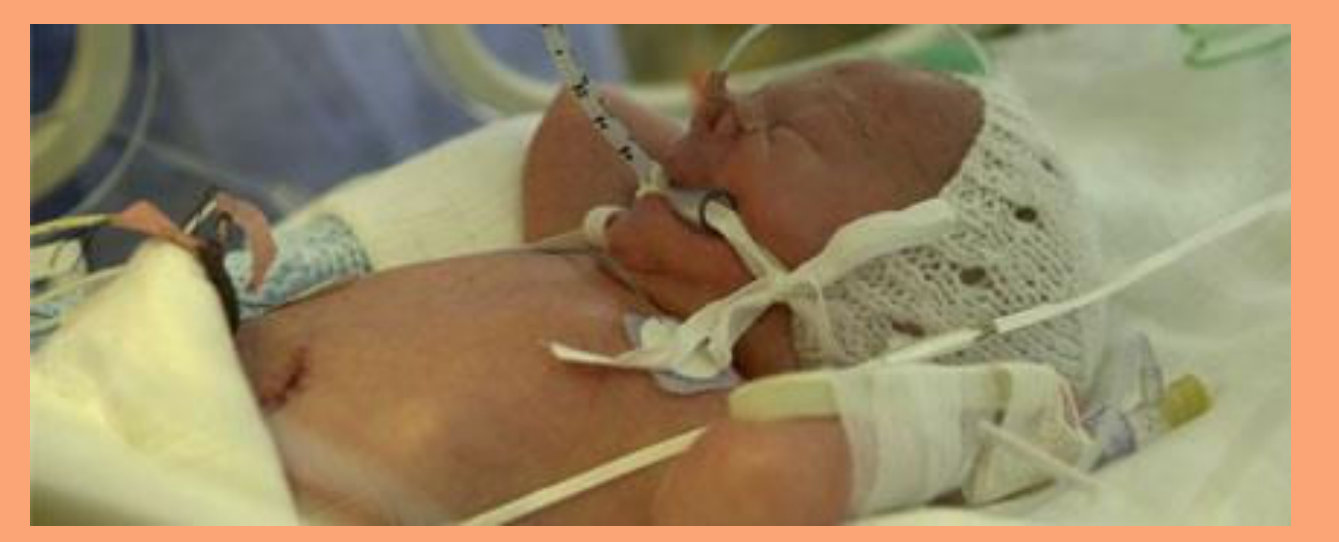

\section{RESULTS AND CONCLUSIONS}

Results of the audit are shown in figure 1.

Adherence to our local probiotic guideline was good for babies <32 weeks' gestation, but relatively poor for more mature preterm VLBW babies who are also at an increased risk for NEC. Reasons for delays or omissions were poorly recorded. Good compliance is important to optimise NEC prevention.

\section{Figure 1}

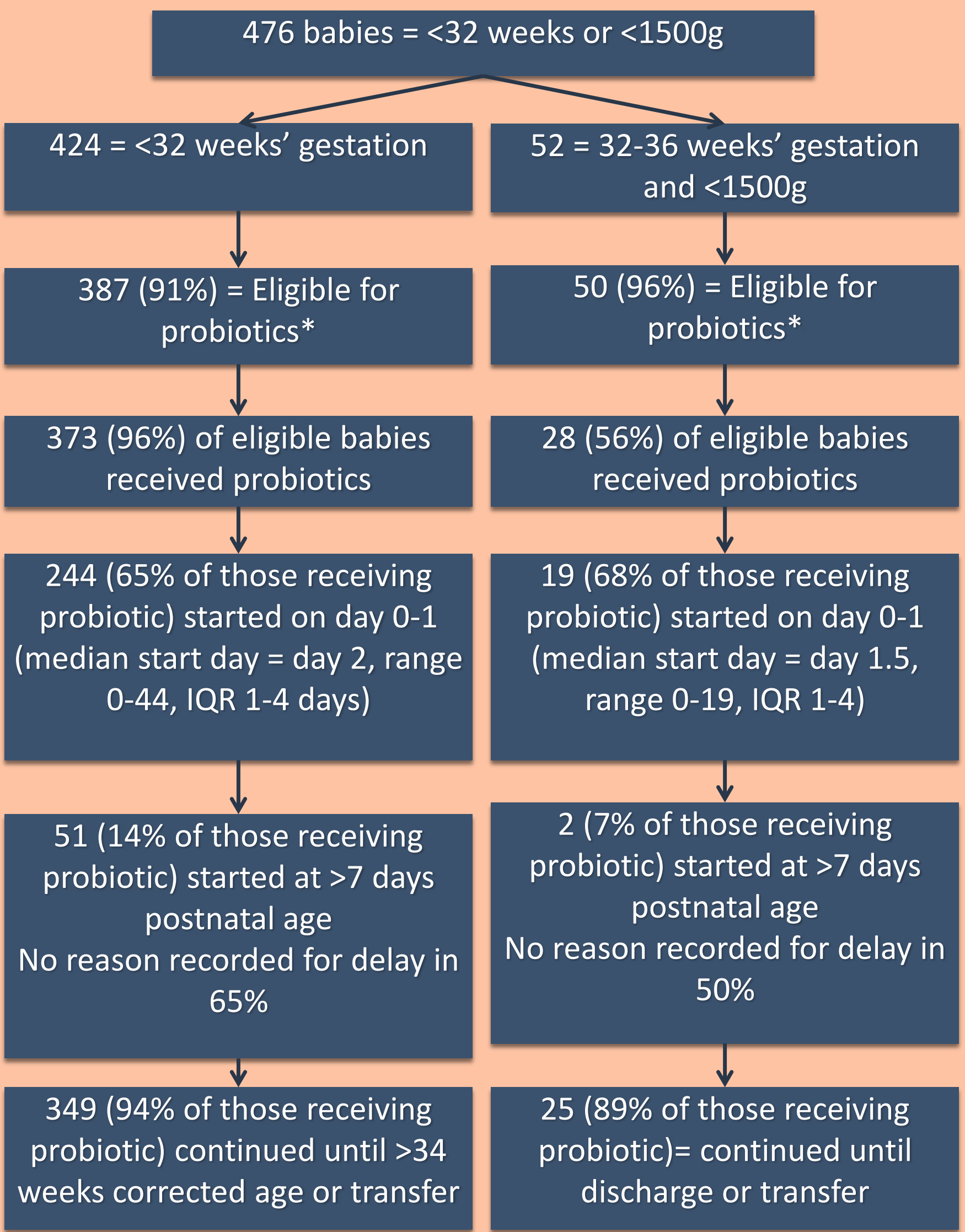

* Exclusion criteria: Seriously unwell (ie not eligible for milk feeds); suspected NEC; sepsis concerns

\section{FUTURE PLANS}

Our audit provides an essential foundation for onward research investigating the effect of routine probiotic administration on the incidence of NEC on our unit.

\section{REFERENCES}

${ }^{1}$ AlFaleh K, Bassler D. Probiotics for prevention of necrotizing enterocolitis in preterm infants (updated 2013). Cochrane Database Syst Rev 2014, Issue 2. ${ }^{2}$ Deshpande G, Rao S, Patole S and Bulsara M. Updated Meta-analysis of Probiotics for Preventing Necrotizing Enterocolitis in Preterm Neonates. Pediatrics 2010;125;921

${ }^{3}$ Samuels, N. et al. Necrotising enterocolitis and mortality in preterm infants after introduction of probiotics: a quasi-experimental study. Sci. Rep. 6, 31643; 